\title{
Optimization and Simultaneous Determination of Alkyl Phenol Ethoxylates and Brominated Flame Retardants in Water after SPE and Heptafluorobutyric Anhydride Derivatization followed by GC/MS
}

\author{
Tlou B. Chokwe $\cdot$ Jonathan O. Okonkwo • \\ Linda L. Sibali $\cdot$ Esper J. Ncube
}

Received: 16 April 2012/Revised: 20 June 2012/Accepted: 2 July 2012/Published online: 16 September 2012

(C) The Author(s) 2012. This article is published with open access at Springerlink.com

\begin{abstract}
A gas chromatography-mass spectrometry (GC-MS) method was investigated for the simultaneous analysis of two types of endocrine disrupting compounds (EDCs), i.e., alkylphenol ethoxylates and brominated flame retardants (BFRs), by extraction and derivatization followed by GC-MS. Different solid phase extraction (SPE) cartridges (Cleanert PestiCarb, $\mathrm{C}_{18}$, Cleanert-SAX and Florosil), solvents (toluene, tetrahydrofuran, acetone, acetonitrile and ethyl acetate) and bases $\left(\mathrm{NaHCO}_{3}\right.$, triethylamine and pyridine) were tested and the best chromatographic analysis was achieved by extraction with Strata-X (33 $\mu \mathrm{m}$, Reverse Phase) cartridge and derivatization with heptafluorobutyric anhydride at $55{ }^{\circ} \mathrm{C}$ under $\mathrm{Na}_{2} \mathrm{CO}_{3}$ base in hexane. It was observed that APE together with lower substituted PBBs (PBB1, PBB10, PBB18 and PBB49), HBCD and TBBPA can be determined simultaneously under the same GC conditions. This simple and reliable analytical method was applied to determining trace amounts of these compounds from wastewater treatment plant samples. The recoveries of the target compounds from simulated water were above $60 \%$. The limit of detection ranged from 0.01 to $0.15 \mu \mathrm{g} \mathrm{L}^{-1}$ and the limit of quantification ranged from 0.05 to $0.66 \mu \mathrm{g} \mathrm{L}^{-1}$. There were no appreciable differences between filtered and unfiltered
\end{abstract}

T. B. Chokwe $(\bowtie) \cdot$ E. J. Ncube

Scientific Services, Rand Water, Vereeniging 1930, South Africa e-mail: tchokwe@randwater.co.za

\section{J. O. Okonkwo}

Department of Environmental, Water and Earth Sciences,

Tshwane University of Technology, Pretoria 0001, South Africa

L. L. Sibali

Directorate of Research and Innovation,

Tshwane University of Technology, Pretoria 0001, South Africa wastewater samples from Leeuwkil treatment plant although concentration of target analytes in filtered influent was slightly lower than the concentration of target analytes in unfiltered influent water. The concentrations of the target compounds from the wastewater treatment were determined from LOQ upwards.

Keywords GC-MS · Heptafluorobutyric anhydride derivatization - Simultaneous determination .

Alkylphenol ethoxylates - Brominated flame retardants . Wastewater effluent and influent samples · Filtration

\section{Introduction}

A number of recent studies have indicated the widespread occurrence of several synthetic organic compounds in wastewater and as a result, significant research efforts have been devoted to their identification [1-4]. Among these compounds, nonylphenol (NP), nonylphenol ethoxylates (NPE), tetrabromobisphenol A (TBBPA), polybrominated diphenyl ethers (PBDEs), hexabromocyclododecane (HBCD) and polybrominated biphenyls (PBBs), present a significant research interest due to their extended use in several consumer and personal-care products and as flame retardants. Studies have shown that APEs and BFRs possess the ability to mimic natural hormones by interacting with the estrogen receptors [5-10]. Consequently, efforts have been made to determine their presence and concentrations in different environmental matrices including aquatic environment [1].

Many reports have been published on the determination of APEs and BFRs using various techniques. Some of the most frequently used methods for the analysis of these groups of compounds include: direct analysis using LC- 
MS [2], GC-ECD [9, 11], GC-FID [6], GC-MS [12], GCMS/MS [13] and GC-HRMS [14, 15]. The use of gas chromatography for the detection of APEs is limited by the scarce volatility of the higher ethoxylated compounds [1619]. On the other hand, the BFRs are volatile enough to be detected using GC, however, high BFRs congeners are very unstable and tend to decompose into lower congeners. Derivatization techniques may provide the answer to the simultaneous detection of these compounds in environmental matrices since derivatization has been used to volatilize non-volatile compounds and stabilize compounds that may undergo partial decomposition in the GC [19].

Several derivatization methods, such as acetylation, silylation and alkylation [16-22], have been used for the GC-MS analysis of phenolic compounds. Acetylation and methylation techniques are suitable for the analytes with high molecular weights. For the group of compounds covered in the present study, acetylation was used because of its quantitative reactions with various hydroxyl compounds at relatively moderate conditions. Among numerous acetylation reagents for derivatization of the hydroxyl group, 1-(trifluoroacetyl) imidazole (TFAI), heptafluorobutyric anhydride (HFBA) and pentafluoropropionic anhydride (PFPA) have widely been used [23]. The use of HFBA as a derivatizing agent for the determination of TBBPA in environmental samples has been reported [23], but never in the presence of APEs in wastewater samples.

This paper, therefore, reports on a simple and reliable procedure, based on SPE followed by HFBA derivatization and gas chromatography-mass spectrometry, for the simultaneous determination of APEs and BFRs in influent and effluent environmental samples obtained from a

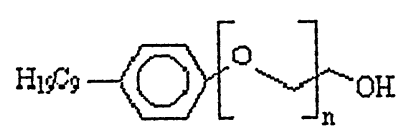

NPnEOS

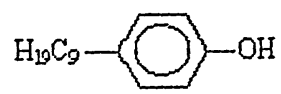

$\mathrm{NP}$

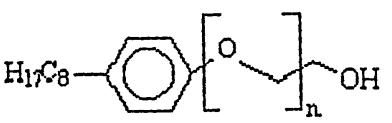

OPnEOS

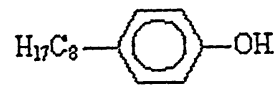

$\mathrm{OP}$
Fig. 1 Structures of common APEs (nonyl- and octyl-phenol ethoxylates) and their metabolites wastewater treatment plant.The approach adopted in the present study is seen to save analyses time and sample handling. Moreover, the impact of filtration of samples on the recoveries of these compounds in real samples was investigated (Figs. 1, 2).

\section{Experimental}

Standards and Reagents

Derivatizing agents, heptafluoro butyric anhydride (HFBA) and pentafluoro propionic anhydride (PFPA) were of analytical grade purchased from Sigma-Aldrich, South Africa. The solvents, acetone and hexane, used in the study were of GC grade and were used without further purification. The APEs and PBBs were purchased from Laboratories Dr. Ehrenstorfer-Schäfers, Augsburg, Germany. Only the NPE, NPPE and OPPE were of technical grade and the remaining APEs and PBBs were of analytical grade. Tetrabromo bisphenol A of technical grade as Firemaster BP4A and hexabromo cyclododecane of technical grade were purchased from AccuStandard, USA. Helium as He 5.5 pure was purchased from Air Product South Africa, Vereeniging.

\section{Method Development}

\section{Derivatization Using HFBA}

Into a vial, APs $\left(1 \mathrm{mg} \mathrm{L}^{-1}\right)$, APEs $\left(4 \mathrm{mg} \mathrm{L}^{-1}\right)$, PBBs $\left(1 \mathrm{mg} \mathrm{L}^{-1}\right), \operatorname{HBCD}\left(2 \mathrm{mg} \mathrm{L}^{-1}\right)$, and TBBPA $\left(4 \mathrm{mg} \mathrm{L}^{-1}\right)$, $1 \mathrm{~mL}$ hexane, $10.5 \mathrm{mg} \mathrm{Na} \mathrm{CO}_{3}$ and $75 \mu \mathrm{L}$ HFBA were added and the content heated to $55{ }^{\circ} \mathrm{C}$ for $2 \mathrm{~h}$ and the derivatization was completed. Thereafter, the contents were cooled and the carbonate quenched with water. The organic phase was then drawn off and the volume made up to $1 \mathrm{~mL}$ with hexane. Thereafter, $1 \mu \mathrm{L}$ was injected into the gas chromatography-mass spectroscopy for analysis.

Instrumentation and GC-MS Conditions

An Agilent 6890 GC equipped with 5973 mass selective detector (MSD) was used for GC/MS analysis. The GC was equipped with a Gerstel autosampler. The injection port
Fig. 2 Structure of a TBBPA, b $\mathrm{PBBs}$ and $\mathbf{c} \mathrm{HBCD}$ a<smiles>CC(C)(c1cc(Br)c(O)c(Br)c1)c1cc(Br)c(O)c(Br)c1</smiles>

b

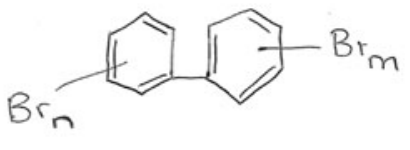

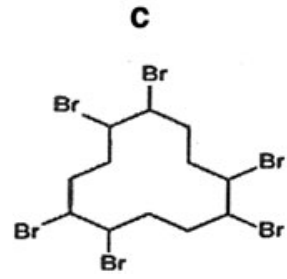


was fitted with a Cyclo Double Gooseneck 4 mm ID deactivated inlet liner (Restek, for Agilent GCs). The GC separation was initially conducted using 30 and $15 \mathrm{~m} \mathrm{DB5}$ with film thickness of $0.25 \mathrm{~mm}$ and internal diameter of $0.25 \mu \mathrm{m}$ capillary column and later with Restek RTx-1614, capillary column (film thickness $0.10 \mu \mathrm{m}, 15 \mathrm{~m} \times 0.25 \mathrm{~mm}$ ID), (Chromspec cc South Africa). The GC-MS conditions used for analysis were as follows: carrier gas, He; linear velocity, $40 \mathrm{~cm} \mathrm{~s}^{-1}$; injector temperature, $275^{\circ} \mathrm{C}$; transfer line temperature, $300{ }^{\circ} \mathrm{C}$; ion source, $150{ }^{\circ} \mathrm{C}$. For analysis, $1 \mu \mathrm{L}$ splitless injection was carried out by autosampler. The GC temperature program conditions were as follows: initial temperature $50{ }^{\circ} \mathrm{C}$, heated to $120{ }^{\circ} \mathrm{C}$ by a temperature ramp of $7.5^{\circ} \mathrm{C} / \mathrm{min}$ then $275^{\circ} \mathrm{C}$ by a temperature ramp of $15^{\circ} \mathrm{C} /$ min then finally heated to $300{ }^{\circ} \mathrm{C}$ (held for $2 \mathrm{~min}$ ) by a temperature ramp of $25^{\circ} \mathrm{C} \mathrm{min}^{-1}$.

\section{SPE and Derivatization of APEs and BFRs in MilliQ} Water Sample

About $250 \mathrm{~mL}$ of MilliQ water acidified to $\mathrm{pH} 3$ with acetic acid was spiked with $100 \mu$ of standard, APs $\left(1 \mathrm{mg} \mathrm{L}^{-1}\right)$, $\operatorname{APEs}\left(4 \mathrm{mg} \mathrm{L}^{-1}\right), \operatorname{PBBs}\left(1 \mathrm{mg} \mathrm{L}^{-1}\right), \operatorname{HBCD}\left(2 \mathrm{mg} \mathrm{L}^{-1}\right)$ and TBBPA (4 mg $\left.\mathrm{L}^{-1}\right)$, then extracted using SPE cartridge (Strata-X $33 \mu \mathrm{m}$ polymeric reversed phase, $500 \mathrm{mg} / 6 \mathrm{~mL}$ ). Before use, the SPE cartridge was conditioned with $6 \mathrm{~mL}$ of $30 \% \mathrm{MeOH}$ in DCM followed by the addition of $6 \mathrm{~mL}$ of $\mathrm{MeOH}$ at a flow rate of approximately $10 \mathrm{~mL} \mathrm{~min}^{-1}$. The sample was loaded into the conditioned cartridge by suction by means of a vacuum pump and, thereafter, the cartridge was dried for $1 \mathrm{~h}$ under vacuum. The compounds were eluted with $3 \times 2 \mathrm{~mL}$ of mixture of DCM-hexane (4:1). The elutes collected were reduced to dryness under a gentle stream of nitrogen and then subjected to the derivatization and GC-MS analysis as described above.

\section{Limits of Detection and Quantification of Analytes}

The instrument detection limit (IDL) was computed using the method described by Miller and Miller [24] given by the following equation:

$\mathrm{IDL}=Y_{\mathrm{b}}+3 S_{\mathrm{b}}$

where $Y_{\mathrm{b}}$ is the blank value and $S_{\mathrm{b}}$ is the standard error of the regression line. The noise and thresholds were set during column background run so as to eliminate noise spikes from being registered as peaks.

\section{Quantification of Analytes}

The targeted analytes were quantified by peak area abundance using external standard method. A five point calibration curves were linear $\left(r^{2}=0.98\right)$ across the concentration range of $0.2-1.0 \mu \mathrm{g} \mathrm{L}^{-1}$.

\section{Water Sample Collection and Extraction}

\author{
Wastewater Sample Collection
}

Environmental water samples were collected from the Leeuwkuil wastewater treatment plant located in the Vereeniging region, South Africa. Water samples were collected at the inlet (influent) and at outlet (effluent) using Winchester $250 \mathrm{~mL}$ brown bottle. The samples were acidified and placed in cooler bags, transported to the laboratory and stored in cold room set at a temperature of $4{ }^{\circ} \mathrm{C}$. The samples were allowed to equilibrate at room temperature before use.

Extraction and Derivatization of APEs and BFRs in Wastewater Sample

A total of $250 \mathrm{~mL}$ wastewater samples were collected from influent and effluent sources from a wastewater treatment plant. The influent samples were divided into filtered and unfiltered samples. The influent sample was first filtered and then spiked with APEs and BFRs standards, and spiked and then filtered. The filtration was carried out using Buchner flask fitted with a $0.47 \mu \mathrm{m}$ pore size. The acidified wastewater samples were then subjected to the extraction and derivatization procedures as described earlier.

\section{Quality Control and Quality Assurance}

The spiking method was used in the quality assurance process of analytical method due to unavailability of certified reference material for target compounds. Simulated water sample was spiked with $100 \mu \mathrm{L}$ of standard mixture of $1.0 \mu \mathrm{g} \mathrm{L}^{-1}$ APs and PBBs; $2.0 \mu \mathrm{g} \mathrm{L}^{-1}$ HBCD and $4.0 \mu \mathrm{g} \mathrm{L}^{-1}$ APEs and TBBPA. The mixture was taken through the same extraction and derivatization procedure mentioned above prior to GC analysis. Quality assurance measures used in this study included running blanks with each sample set.

\section{Data Analysis}

All samples were prepared in triplicate and from the triplicate measurement the mean concentrations were calculated and expressed as $\mu \mathrm{g} \mathrm{\textrm {L } ^ { - 1 }}$. The mean and standard deviation were calculated from the measurements. 


\section{Results and Discussions}

\section{Derivatization}

In order to improve the selectivity and sensitivity of detection, phenolic compounds are often derivatized prior to GC-MS analysis [21]. Using nonylphenol as a benchmark for derivatization, different derivatization agents [1-(trifluoroacetyl) imidazole (TFAI), pentafluoropropionic anhydride (PFPA) and heptafluorobutyric anhydride (HFBA)], solvents (hexane, acetonitrile, toluene and acetone) and bases $\left(\mathrm{NaHCO}_{3}, \mathrm{Na}_{2} \mathrm{CO}_{3}\right.$, pyridine and triethylamine) were compared in order to find optimal conditions for the derivatization of the targeted analytes. In the experiments conducted, it was observed that both the PFPA and HBFA in hexane with $\mathrm{Na}_{2} \mathrm{CO}_{3}$ as base provided stable derivatives, while the TFAI derivative was milky necessitating a further clean-up step. For further experiments, derivatization with HFBA was chosen because of quantitative reaction, the formation of stable products and availability of the agent. Figure 3 shows a nonylphenol HFBA derivative chromatogram obtained with a $30 \mathrm{~m}$ long DB5 column with EI-mass spectra.
The APEs where derivatized simultaneously using the optimized conditioned obtained from nonylphenol and the chromatogram is presented in Fig. 4. The change in retention time for nonylphenol was due to the use of a shorter column (15 m DB5). The change to a shorter column was to minimize the degradation of the products during analysis.

However, when the APs were analyzed together with PBBs (1, 10, 18 and 49), there was a co-elution of NP and PBB10 using a temperature ramp of $15{ }^{\circ} \mathrm{C} / \mathrm{min}$ from 50 to $120^{\circ} \mathrm{C}$ as shown in Fig. 5. As seen from Fig. 5, the sensitivity of PBB10 was low from the EI-mass fragmentation.

When this temperature ramp was reduced from 15 to $7.5^{\circ} \mathrm{C} / \mathrm{min}$, the two compounds were separated. The ramp condition was, therefore, kept at $7.5^{\circ} \mathrm{C} / \mathrm{min}$ throughout the study. Due to low peak area abundance of PBBs from the EI-mass fragmentation, RTs 1614 column $(15 \mathrm{~m})$ was used in place of the DB5 $(15 \mathrm{~m})$ and was used further during the course of the analysis. The selected APEs and TBBPA were derivatized simultaneously in the presence of PBBs, (1, 10, 18 and 49) and HBCD as presented in Fig. 5.

Although both the NPE and NPPE were used as technical mixtures, it was easy to identify their masses in the

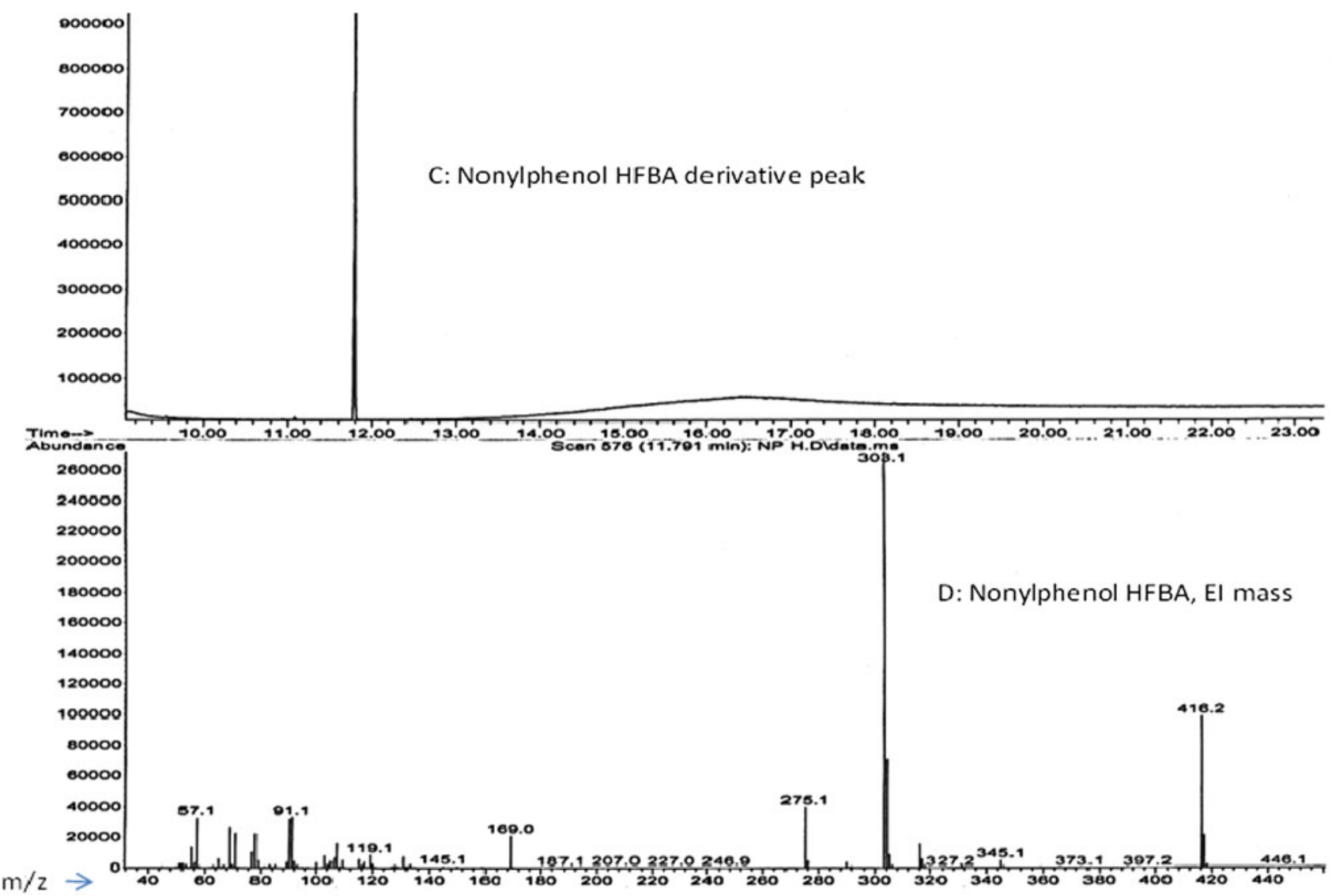

Fig. 3 The $C$ gas chromatogram and $D$ EI-mass spectra of nonylphenol-HFBA derivative 
Fig. 4 The GC chromatogram of derivatized APEs
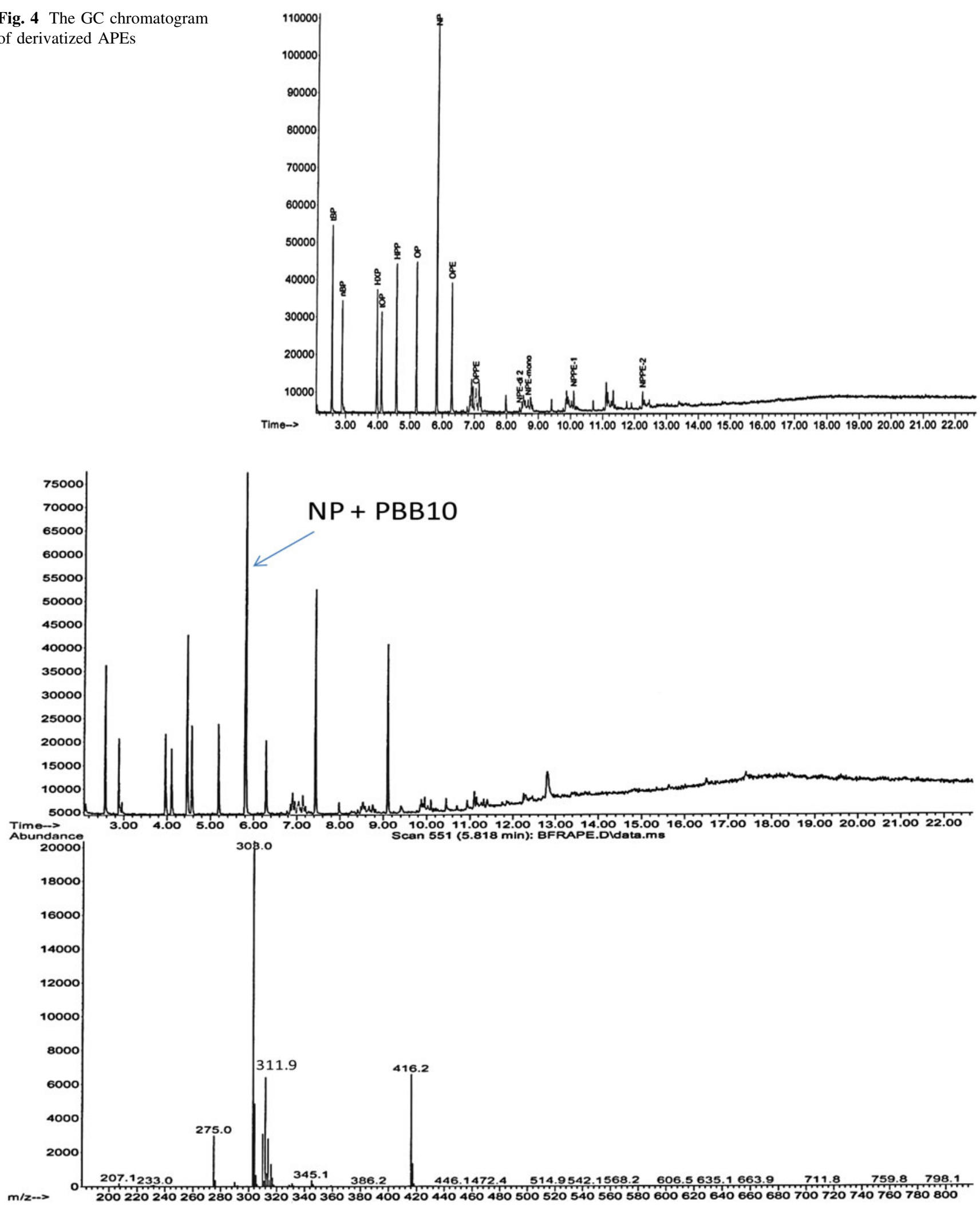

Fig. 5 GC chromatogram and EI-mass spectra showing co-elution of PBB10 with NP 


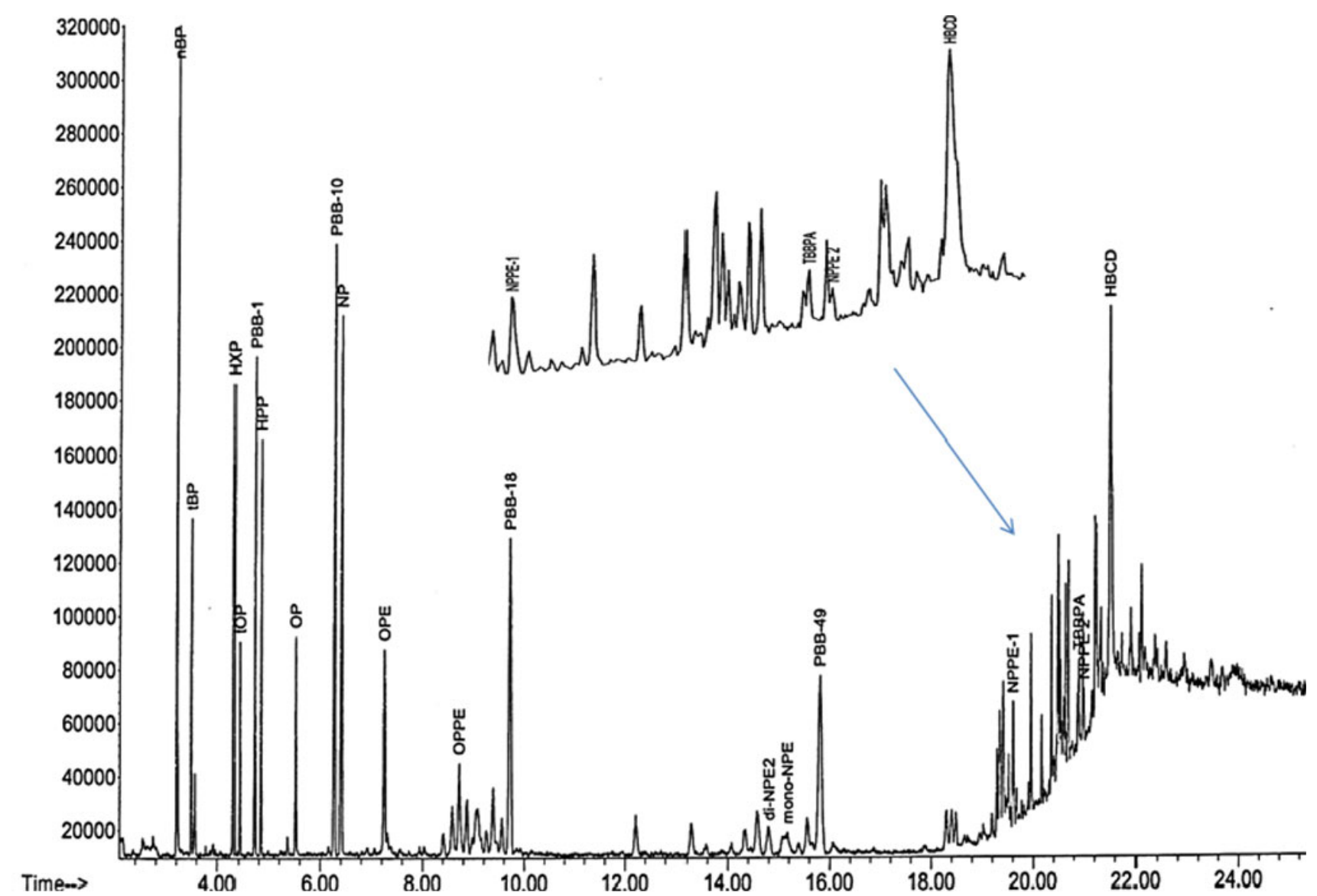

Fig. 6 GC chromatogram of derivatized APEs and TBBPA in the presence of PBBs and HBCD

chromatograph (Fig. 6). It was observed that the NPE comprised nonylphenol ethoxylate (mono-NPE) and nonylphenol di-ethoxylate (di-NPE). The $\mathrm{M}^{+}$ions used to identify the NPE, as shown in Table 1, were 433.2, 419 and 461 for mono-ethoxylate and 419, 475, 405, 433, and 504 for di-ethoxylate. There were also two sets of the pentaethoxylate. The ions used to differentiate between the two penta-ethoxylates were 463, 477, 519 and 639 and the other was 551, 565, 607 and 639 and well separated (19.629 and $20.982 \mathrm{~min}$ ). This additional fingerprint information may be very useful for the identification of these compounds in the complex matrix environmental samples. It was also observed that derivatization depended on the analyte structure, time and solvent. In this study, the derivatization reaction for the phenolic hydroxyl group was completed faster than that for the alcoholic hydroxyl groups. This phenomenon has been observed by Hoai et al. [18].

Solid phase extraction is the most widely used preconcentration procedure. It is used not only to extract traces of organic compounds from environmental samples but also to remove interfering components from the matrix [1]. The performances of four different types of cartridges were initially examined using initially $1,000 \mathrm{~mL}$ spiked water (data shown for 4 cartridges, Table 2). Strata-X gave better
Table 1 Ions for selected ion monitoring of heptaflourobutyric derivatives

\begin{tabular}{lcll}
\hline Analyte & $\begin{array}{l}\text { Retention } \\
\text { time (min) }\end{array}$ & $\begin{array}{l}\text { Quantification ion } \\
\text { (abundance) }\end{array}$ & $\begin{array}{l}\text { Confirmation ions } \\
\text { (abundance) }\end{array}$ \\
\hline$t$-BP & 3.202 & 331 & 346 \\
$\mathrm{n}$-BP & 3.494 & 303 & 346 \\
HXP & 4.278 & 303 & 374.1 \\
$t$-OP & 4.481 & 331 & \\
PBB-1 & 4.776 & 232 & \\
HPP & 4.824 & 303 & 388.1 \\
OP & 5.644 & 303 & 402 \\
PBB-10 & 6.267 & 311.9 & \\
NP & 6.423 & 303 & 416.2 \\
OPE & 7.177 & 375 & 446 \\
OPPE & 8.858 & 389.1 & $375 ; 431 ; 361 ; 615$ \\
PBB-18 & 9.645 & 389.8 & $310.9 ; 232.0$ \\
PBB-49 & 15.802 & 469.7 & $390.8 ; 309.8$ \\
di-NPE2 & 14.636 & 419 & $433.1 ; 475 ; 405 ; 504$ \\
di-NPE1 & 15.803 & 433.2 & $419 ; 475 ; 405 ; 504$ \\
mono-NPE & 15.190 & 433.2 & $419 ; 461$ \\
NPPE1 & 19.628 & 463.1 & $477.1 ; 519.3$ \\
TBBPA & 20.848 & 726 & 565,607 \\
NPPE2 & 20.982 & 551 & $400.8 ; 319 ; 239$ \\
HBCD & 21.541 & 562.8 & \\
\hline & & & \\
\hline
\end{tabular}


Table 2 Extraction results from four types of SPE cartridges

\begin{tabular}{|c|c|c|c|c|c|c|c|c|c|}
\hline \multirow[t]{2}{*}{ Compound } & \multicolumn{5}{|l|}{$\mu \mathrm{g} \mathrm{L}^{-1}$} & \multicolumn{4}{|c|}{$\%$ Recovery } \\
\hline & Exp. conc. & Strata-X & PestCarb & Florisil & $\mathrm{C} 18$ & Strata-X & PestCarb & $\mathrm{C} 18$ & Florisil \\
\hline$t$-BP & 0.40 & 0.06 & 0.01 & 0.00 & 0.00 & 15.00 & 2.50 & 0.00 & 0.00 \\
\hline n-BP & 0.40 & 0.24 & 0.22 & 0.36 & 0.42 & 60.00 & 55.00 & 105.00 & 90.00 \\
\hline HXP & 0.40 & 0.24 & 0.01 & 0.03 & 0.04 & 60.00 & 2.50 & 10.00 & 7.50 \\
\hline$t$-OP & 0.40 & 0.23 & 0.02 & 0.05 & 0.05 & 57.50 & 5.00 & 12.50 & 12.50 \\
\hline PBB-1 & 0.20 & 0.01 & 0.15 & 0.00 & 0.00 & 5.00 & 75.00 & 0.00 & 0.00 \\
\hline HPP & 0.40 & 0.29 & 0.02 & 0.06 & 0.16 & 72.50 & 5.00 & 40.00 & 15.00 \\
\hline OP & 0.40 & 0.27 & 0.01 & 0.05 & 0.24 & 67.50 & 2.50 & 60.00 & 12.50 \\
\hline PBB-10 & 0.20 & 0.04 & 0.15 & 0.05 & 0.01 & 20.00 & 75.00 & 5.00 & 25.00 \\
\hline NP & 0.40 & 0.19 & 0.01 & 0.08 & 0.25 & 47.50 & 2.50 & 62.50 & 20.00 \\
\hline OPE & 0.40 & 0.43 & 0.34 & 0.42 & 0.42 & 107.50 & 85.00 & 105.00 & 105.00 \\
\hline OPPE & 1.60 & 1.54 & 1.21 & 1.37 & 1.35 & 96.25 & 75.63 & 84.38 & 85.63 \\
\hline PBB-18 & 0.20 & 0.05 & 0.16 & 0.10 & 0.09 & 25.00 & 80.00 & 45.00 & 50.00 \\
\hline PBB-49 & 0.20 & 0.05 & 0.21 & 0.13 & 0.17 & 25.00 & 105.00 & 85.00 & 65.00 \\
\hline di-NPE2 & 1.60 & 1.09 & 1.02 & 1.02 & 1.45 & 68.13 & 63.75 & 90.63 & 63.75 \\
\hline di-NPE1 & 1.60 & 0.79 & 0.62 & 0.61 & 0.86 & 49.38 & 38.75 & 53.75 & 38.13 \\
\hline mono-NPE & 1.60 & 1.14 & 0.88 & 0.97 & 1.20 & 71.25 & 55.00 & 75.00 & 60.63 \\
\hline NPPE1 & 1.60 & 0.29 & 0.36 & 0.25 & 0.39 & 18.13 & 22.50 & 24.38 & 15.63 \\
\hline TBBPA & 1.60 & 1.52 & 0.18 & 0.23 & 0.53 & 95.00 & 11.25 & 33.13 & 14.38 \\
\hline NPPE2 & 1.60 & 0.21 & 0.19 & 0.25 & 0.16 & 13.13 & 11.88 & 10.00 & 15.63 \\
\hline HBCD & 0.80 & 1.37 & 2.86 & 2.15 & 3.56 & 171.25 & 357.50 & 445.00 & 268.75 \\
\hline
\end{tabular}

Cartridges conditioned with $5 \mathrm{~mL}$ ethyl acetate followed by $5 \mathrm{~mL} \mathrm{MeOH}$ and $5 \mathrm{~mL}$ acidified water (pH 3 with $\mathrm{HCl}$ ) and eluted with $3 \times 2 \mathrm{~mL}$ ethyl acetate

Table 3 Effect of $\mathrm{MeOH}$ addition during SPE of APEs and BFRs

\begin{tabular}{|c|c|c|c|c|c|c|c|c|}
\hline \multirow[t]{2}{*}{ Compound } & \multirow[t]{2}{*}{ RT (min) } & \multirow[t]{2}{*}{ Exp. conc. } & \multicolumn{3}{|c|}{ Conc. $\left(\mu \mathrm{g} \mathrm{L}^{-1}\right)$} & \multicolumn{3}{|c|}{$\%$ Recovery } \\
\hline & & & $1 \mathrm{~mL}$ & $2.5 \mathrm{~mL}$ & $5 \mathrm{~mL}$ & $1 \mathrm{~mL}$ & $2.5 \mathrm{~mL}$ & $5 \mathrm{~mL}$ \\
\hline$t$-BP & 3.202 & 0.400 & 0.27 & 0.33 & 0.25 & 67.50 & 82.50 & 62.50 \\
\hline $\mathrm{n}-\mathrm{BP}$ & 3.494 & 0.400 & 0.28 & 0.31 & 0.26 & 70.00 & 77.50 & 65.00 \\
\hline HXP & 4.278 & 0.400 & 0.37 & 0.28 & 0.35 & 92.50 & 70.00 & 87.50 \\
\hline$t$-OP & 4.481 & 0.400 & 0.34 & 0.25 & 0.32 & 85.00 & 62.50 & 80.00 \\
\hline PBB-1 & 4.776 & 0.400 & 0.11 & 0.26 & 0.07 & 27.50 & 65.00 & 17.50 \\
\hline HPP & 4.824 & 0.400 & 0.28 & 0.21 & 0.28 & 70.00 & 52.50 & 70.00 \\
\hline $\mathrm{OP}$ & 5.644 & 0.400 & 0.32 & 0.35 & 0.35 & 80.00 & 87.50 & 87.50 \\
\hline PBB-10 & 6.267 & 0.400 & 0.36 & 0.39 & 0.38 & 90.00 & 97.50 & 95.00 \\
\hline NP & 6.423 & 0.400 & 0.24 & 0.27 & 0.27 & 60.00 & 67.50 & 67.50 \\
\hline OPE & 7.177 & 0.400 & 0.53 & 0.40 & 0.59 & 132.50 & 100.00 & 147.50 \\
\hline OPPE & 8.858 & 1.600 & 1.8 & 1.34 & 2.31 & 112.50 & 83.75 & 144.38 \\
\hline PBB-18 & 9.645 & 0.400 & 0.28 & 0.31 & 0.37 & 70.00 & 77.50 & 92.50 \\
\hline PBB-49 & 15.802 & 0.400 & 0.04 & 0.19 & 0.04 & 10.00 & 47.50 & 10.00 \\
\hline di-NPE2 & 14.636 & 1.600 & 3.03 & 2.05 & 4.49 & 189.38 & 128.13 & 280.63 \\
\hline di-NPE1 & 14.802 & 1.600 & 2.98 & 1.61 & 3.86 & 186.25 & 100.63 & 241.25 \\
\hline mono-NPE & 15.190 & 1.600 & 2.87 & 1.64 & 0.95 & 179.38 & 102.50 & 59.38 \\
\hline NPPE1 & 19.629 & 1.600 & 3.21 & 3.85 & 2.56 & 200.63 & 240.63 & 160.00 \\
\hline TВBPA & 20.848 & 1.600 & 1.02 & 1.23 & 1.31 & 63.75 & 76.88 & 81.88 \\
\hline NPPE2 & 20.982 & 1.600 & 3.12 & 1.26 & 1.06 & 195.00 & 78.75 & 66.25 \\
\hline HBCD & 21.541 & 0.800 & 0.53 & 0.54 & 0.32 & 66.25 & 67.50 & 40.00 \\
\hline
\end{tabular}


Table 4 The effect of washing cartridges after extraction step

\begin{tabular}{|c|c|c|c|c|c|c|c|c|c|c|}
\hline \multirow[t]{2}{*}{ Compound } & \multirow[t]{2}{*}{ RT (min) } & \multirow[t]{2}{*}{ Exp. conc. } & \multicolumn{4}{|c|}{ Conc. $\left(\mu \mathrm{g} \mathrm{L}^{-1}\right)$} & \multicolumn{4}{|c|}{$\%$ Recovery } \\
\hline & & & $0 \mathrm{~mL}$ & $5 \mathrm{~mL}$ & $10 \mathrm{~mL}$ & $15 \mathrm{~mL}$ & $0 \mathrm{~mL}$ & $5 \mathrm{~mL}$ & $10 \mathrm{~mL}$ & $15 \mathrm{~mL}$ \\
\hline$t$-BP & 3.202 & 0.400 & 0.33 & 0.35 & 0.31 & 0.31 & 82.50 & 87.50 & 77.50 & 77.50 \\
\hline n-BP & 3.494 & 0.400 & 0.36 & 0.36 & 0.33 & 0.33 & 90.00 & 90.00 & 82.50 & 82.50 \\
\hline HXP & 4.278 & 0.400 & 0.36 & 0.36 & 0.4 & 0.35 & 90.00 & 90.00 & 100.00 & 87.50 \\
\hline$t$-OP & 4.481 & 0.400 & 0.39 & 0.38 & 0.4 & 0.35 & 97.50 & 95.00 & 100.00 & 87.50 \\
\hline PBB-1 & 4.776 & 0.400 & 0.21 & 0.07 & 0.09 & 0.07 & 52.50 & 17.50 & 22.50 & 17.50 \\
\hline HPP & 4.824 & 0.400 & 0.33 & 0.34 & 0.35 & 0.3 & 82.50 & 85.00 & 87.50 & 75.00 \\
\hline OP & 5.644 & 0.400 & 0.33 & 0.35 & 0.35 & 0.31 & 82.50 & 87.50 & 87.50 & 77.50 \\
\hline PBB-10 & 6.267 & 0.400 & 0.53 & 0.3 & 0.51 & 0.36 & 132.50 & 75.00 & 127.50 & 90.00 \\
\hline NP & 6.423 & 0.400 & 0.25 & 0.23 & 0.27 & 0.23 & 62.50 & 57.50 & 67.50 & 57.50 \\
\hline OPE & 7.177 & 0.400 & 0.53 & 0.49 & 0.54 & 0.44 & 132.50 & 122.50 & 135.00 & 110.00 \\
\hline OPPE & 8.858 & 1.600 & 1.72 & 1.56 & 1.85 & 1.57 & 107.50 & 97.50 & 115.63 & 98.13 \\
\hline PBB-18 & 9.645 & 0.400 & 0.34 & 0.27 & 0.34 & 0.3 & 85.00 & 67.50 & 85.00 & 75.00 \\
\hline PBB-49 & 15.802 & 0.400 & 0.24 & 0.03 & 0.04 & 0.03 & 60.00 & 7.50 & 10.00 & 7.50 \\
\hline di-NPE2 & 14.636 & 1.600 & 2.22 & 2.06 & 2.09 & 1.76 & 138.75 & 128.75 & 130.63 & 110.00 \\
\hline di-NPE1 & 14.802 & 1.600 & 2.09 & 2.26 & 3.16 & 2.25 & 130.63 & 141.25 & 197.50 & 140.63 \\
\hline mono-NPE & 15.190 & 1.600 & 2.61 & 2.7 & 2.64 & 1.97 & 163.13 & 168.75 & 165.00 & 123.13 \\
\hline NPPE1 & 19.629 & 1.600 & 2.85 & 3.56 & 3.65 & 4.32 & 178.13 & 222.50 & 228.13 & 270.00 \\
\hline TBBPA & 20.848 & 1.600 & 0.76 & 0.79 & 0.52 & 0.35 & 47.50 & 49.38 & 32.50 & 21.88 \\
\hline NPPE2 & 20.982 & 1.600 & 1.95 & 0.65 & 0.58 & 0.85 & 121.88 & 40.63 & 36.25 & 53.13 \\
\hline HBCD & 21.541 & 0.800 & 0.58 & 0.22 & 0.3 & 0.41 & 72.50 & 27.50 & 37.50 & 51.25 \\
\hline
\end{tabular}

$R T$ retention time

Table 5 Recoveries of APEs and BFRs in MilliQ water $(n=3)$

\begin{tabular}{lrllc}
\hline Compound & $\begin{array}{l}\text { RT } \\
(\mathrm{min})\end{array}$ & $\begin{array}{l}\text { Expected conc. } \\
\left(\mu \mathrm{g} \mathrm{L}^{-1}\right)\end{array}$ & $\begin{array}{l}\text { Conc. }(\mu \mathrm{g} \\
\left.\mathrm{L}^{-1}\right)\end{array}$ & $\begin{array}{l}\text { Relative } \\
\text { recovery }(\%)\end{array}$ \\
\hline$t$-BP & 3.202 & 0.400 & $0.36 \pm 0.035$ & $90.00 \pm 8.84$ \\
$\mathrm{n}$-BP & 3.494 & 0.400 & $0.36 \pm 0.014$ & $90.00 \pm 1.41$ \\
$\mathrm{HXP}$ & 4.278 & 0.400 & $0.39 \pm 0.042$ & $95.50 \pm 10.61$ \\
$t$-OP & 4.481 & 0.400 & $0.41 \pm 0.028$ & $102.00 \pm 7.07$ \\
PBB-1 & 4.776 & 0.400 & $0.26 \pm 0.028$ & $65.00 \pm 7.07$ \\
HPP & 4.824 & 0.400 & $0.36 \pm 0.035$ & $90.00 \pm 8.84$ \\
OP & 5.644 & 0.400 & $0.36 \pm 0.035$ & $90.00 \pm 8.84$ \\
PBB-10 & 6.267 & 0.400 & $0.56 \pm 0.035$ & $138.50 \pm 9.19$ \\
NP & 6.423 & 0.400 & $0.27 \pm 0.021$ & $66.25 \pm 5.30$ \\
OPE & 7.177 & 0.400 & $0.56 \pm 0.042$ & $140.00 \pm 7.78$ \\
OPPE & 8.858 & 1.600 & $1.75 \pm 0.042$ & $109.38 \pm 2.65$ \\
PBB-18 & 9.645 & 0.400 & $0.33 \pm 0.014$ & $82.50 \pm 3.53$ \\
PBB-49 & 15.802 & 0.400 & $0.27 \pm 0.014$ & $66.25 \pm 5.30$ \\
di-NPE2 & 14.636 & 1.600 & $2.23 \pm 0.014$ & $139.38 \pm 0.88$ \\
di-NPE1 & 14.802 & 1.600 & $2.13 \pm 0.353$ & $133.13 \pm 20.33$ \\
mono- & 15.190 & 1.600 & $2.68 \pm 0.071$ & $167.82 \pm 6.63$ \\
NPE & & & & \\
NPPE1 & 19.629 & 1.600 & $2.10 \pm 0.071$ & $131.25 \pm 4.24$ \\
TBBPA & 20.848 & 1.600 & $1.12 \pm 0.007$ & $69.69 \pm 0.44$ \\
NPPE2 & 20.982 & 1.600 & $2.40 \pm 1.704$ & $110.32 \pm 35.36$ \\
HBCD & 21.541 & 0.800 & $0.61 \pm 0.014$ & $76.25 \pm 2.83$ \\
\hline & & & &
\end{tabular}

recoveries for the extraction of APEs, while PestiCarb cartridges gave better recoveries for the extraction of BFRs compared to the other cartridges tested. Cai et al. [25] studied the effect of $\mathrm{pH}$ on extraction efficiencies of similar target analytes and the results showed extraction recovery $(>95 \%)$ for APEs (NP and tert-OP) remains relatively similar at $\mathrm{pH} 3-8$, but recoveries of BPA were dramatically decreased to $60 \%$ at $\mathrm{pH}$ above 8. Hoai et al. [18] reported that simultaneous determination of NPnEOs and their halogenated derivatives at $\mathrm{pH} 2-4$ with $\mathrm{HCl}$ was found to be applicable for the extraction and elution of the analytes. On the basis of their experimental results, $\mathrm{pH}$ range of 3-4 was chosen as the $\mathrm{pH}$ of the sample solutions.

Strata-X and PestiCarb cartridges were subjected to further test in order to select the cartridge with the better performance for all the analytes. It was observed that the Strata gave better extraction efficiency compared to PestiCarb when the former was conditioned with $30 \% \mathrm{MeOH}$ in DCM followed by $\mathrm{MeOH}$ and acidified water (acidified to $\mathrm{pH} 3$ with acetic acid) and the extraction volume reduced from 1,000 to $250 \mathrm{~mL}$.

Sibali et al. (2010) [6] confirmed APE loss by analytes retention in the sample bottle. In order to prevent the retention of analytes from the sample bottle, several volumes of methanol were added to the sample before the 
Table 6 Quantitative calibration and detection limits of analytes

\begin{tabular}{|c|c|c|c|c|}
\hline Compound & $\begin{array}{l}\text { Range of } \\
\text { standards } \\
\left(\mu \mathrm{g} \mathrm{L}^{-1}\right)\end{array}$ & $\begin{array}{l}\text { Correlation } \\
\text { co-efficient }\end{array}$ & $\begin{array}{l}\text { LOD } \\
\left(\mu \mathrm{g} \mathrm{L}^{-1}\right)\end{array}$ & $\begin{array}{l}\text { LOQ } \\
\left(\mu \mathrm{g} \mathrm{L}^{-1}\right)\end{array}$ \\
\hline$t$-BP & $0.2-1.0$ & 0.992 & 0.03 & 0.08 \\
\hline $\mathrm{n}-\mathrm{BP}$ & $0.2-1.0$ & 0.995 & 0.08 & 0.26 \\
\hline HXP & $0.2-1.0$ & 0.991 & 0.03 & 0.09 \\
\hline$t$-OP & $0.2-1.0$ & 0.994 & 0.02 & 0.07 \\
\hline PBB-1 & $0.2-1.0$ & 0.997 & 0.01 & 0.05 \\
\hline HPP & $0.2-1.0$ & 0.995 & 0.02 & 0.07 \\
\hline $\mathrm{OP}$ & $0.2-1.0$ & 0.994 & 0.02 & 0.07 \\
\hline PBB-10 & $0.2-1.0$ & 0.995 & 0.02 & 0.06 \\
\hline NP & $0.2-1.0$ & 0.992 & 0.02 & 0.08 \\
\hline OPE & $0.2-1.0$ & 0.993 & 0.02 & 0.08 \\
\hline OPPE & $0.8-4.0$ & 0.990 & 0.14 & 0.45 \\
\hline PBB-18 & $0.2-1.0$ & 0.991 & 0.03 & 0.08 \\
\hline PBB-49 & $0.2-1.0$ & 0.993 & 0.02 & 0.08 \\
\hline di-NPE2 & $0.8-4.0$ & 0.993 & 0.20 & 0.66 \\
\hline di-NPE1 & $0.8-4.0$ & 0.994 & 0.10 & 0.34 \\
\hline mono-NPE & $0.8-4.0$ & 0.990 & 0.15 & 0.51 \\
\hline NPPE1 & $0.8-4.0$ & 0.997 & 0.07 & 0.23 \\
\hline TBBPA & $0.8-4.0$ & 0.992 & 0.10 & 0.34 \\
\hline NPPE2 & $0.8-4.0$ & 0.986 & 0.13 & 0.42 \\
\hline HBCD & $0.4-2.0$ & 0.996 & 0.03 & 0.11 \\
\hline
\end{tabular}

$L O D$ limit of detection, $L O Q$ limit of quantification enrichment step to minimize this adsorption problem. As shown in Table 3, $1 \%$ methanol $(2.5 \mathrm{~mL} \mathrm{MeOH}$ in $250 \mathrm{~mL}$ sample) gave better results for most of the compounds. Taking into consideration the recoveries of all the analytes, $1 \% \mathrm{MeOH}$ addition was chosen as the best condition.

The results on the effect of washing the cartridge after extraction are tabulated in Table 4. After passing the sample through the cartridge, the cartridge was washed with appropriate amount of water (i.e., 5, 10 and $15 \mathrm{~mL}$ as indicated in Table 4) to remove any interference and then dried for $1 \mathrm{~h}$. The results showed that washing of the cartridges had an overall negative effect on the recoveries of the compounds especially the brominated compounds as their recoveries were the most reduced with increased washing. With APEs, the effect was considered negligible. Based on these observations, cartridge washing step was not incorporated in the extraction of these analytes.

Finally, triplicate extraction and derivatization of analytes were performed under the condition deemed optimum. The condition included the simultaneous derivatization of APEs in the presence of BFRs at $55^{\circ} \mathrm{C}$ with HFBA, $\mathrm{Na}_{2} \mathrm{CO}_{3}$ with hexane as solvent for $2 \mathrm{~h}$. The extraction included the conditioning of Strata-X cartridge with $6 \mathrm{~mL}$ of $30 \% \mathrm{MeOH}$ in DCM followed by addition of $6 \mathrm{~mL}$ of $\mathrm{MeOH}$. The samples were acidified to $\mathrm{pH} 3$ with acetic acid. As shown in Table 5, the percentage recoveries
Table 7 Recoveries of APEs and BFRs in wastewater

Effluent spiked final water leaving the plant spiked, influent spiked filtered raw water entering the plant spiked then filtered, influent filtered spiked raw water filtered then spiked

\begin{tabular}{llclc}
\hline $\begin{array}{l}\text { Corrected data } \\
\text { compound }\end{array}$ & $\begin{array}{l}\text { Expected } \\
\text { conc. }\end{array}$ & $\begin{array}{l}\text { Effluent spiked } \\
\text { relative recovery }(\%)\end{array}$ & $\begin{array}{l}\text { Influent spiked filtered } \\
\text { relative recovery }(\%)\end{array}$ & $\begin{array}{l}\text { Influent filtered spiked } \\
\text { relative recovery }(\%)\end{array}$ \\
\hline$t$-BP & 0.400 & $67.50 \pm 2.02$ & $52.50 \pm 6.23$ & $60.00 \pm 3.33$ \\
n-BP & 0.400 & $60.00 \pm 3.00$ & $50.00 \pm 5.89$ & $57.50 \pm 8.13$ \\
HXP & 0.400 & $70.00 \pm 3.00$ & $52.50 \pm 9.23$ & $60.00 \pm 5.68$ \\
$t$-OP & 0.400 & $52.50 \pm 2.13$ & $47.50 \pm 12.36$ & $55.00 \pm 8.69$ \\
PBB-1 & 0.400 & $65.00 \pm 9.36$ & $60.00 \pm 7.23$ & $62.50 \pm 13.21$ \\
HPP & 0.400 & $62.50 \pm 5.32$ & $62.50 \pm 1.23$ & $60.00 \pm 7.88$ \\
OP & 0.400 & $72.50 \pm 1.25$ & $72.50 \pm 15.23$ & $65.00 \pm 8.85$ \\
PBB-10 & 0.400 & $117.50 \pm 9.19$ & $77.50 \pm 2.31$ & $105.00 \pm 1.23$ \\
NP & 0.400 & $57.50 \pm 3.50$ & $67.50 \pm 7.78$ & $57.50 \pm 5.35$ \\
OPE & 0.400 & $82.50 \pm 7.78$ & $32.50 \pm 5.35$ & $90.00 \pm 2.36$ \\
OPPE & 1.600 & $57.50 \pm 1.89$ & $83.13 \pm 6.23$ & $102.50 \pm 4.23$ \\
PBB-18 & 0.400 & $75.00 \pm 5.33$ & $55.00 \pm 4.23$ & $67.50 \pm 3.98$ \\
PBB-49 & 0.400 & $62.50 \pm 5.30$ & $52.50 \pm 6.23$ & $70.00 \pm 2.05$ \\
di-NPE2 & 1.600 & $75.00 \pm 8.80$ & $80.63 \pm 18.23$ & $96.25 \pm 2.65$ \\
di-NPE1 & 1.600 & $80.00 \pm 12.32$ & $64.38 \pm 9.98$ & $102.50 \pm 2.50$ \\
mono-NPE & 1.600 & $56.88 \pm 6.63$ & $64.38 \pm 3.68$ & $107.50 \pm 3.53$ \\
NPPE1 & 1.600 & $168.75 \pm 4.05$ & $67.50 \pm 4.68$ & $74.38 \pm 4.39$ \\
TBBPA & 1.600 & $72.50 \pm 2.65$ & $58.13 \pm 17.32$ & $52.50 \pm 1.39$ \\
NPPE2 & 1.600 & $53.75 \pm 15.23$ & $89.38 \pm 3.69$ & $76.88 \pm 2.97$ \\
HBCD & 0.800 & $56.25 \pm 8.32$ & $57.50 \pm 7.23$ & $72.50 \pm 8.63$ \\
\hline & & & &
\end{tabular}




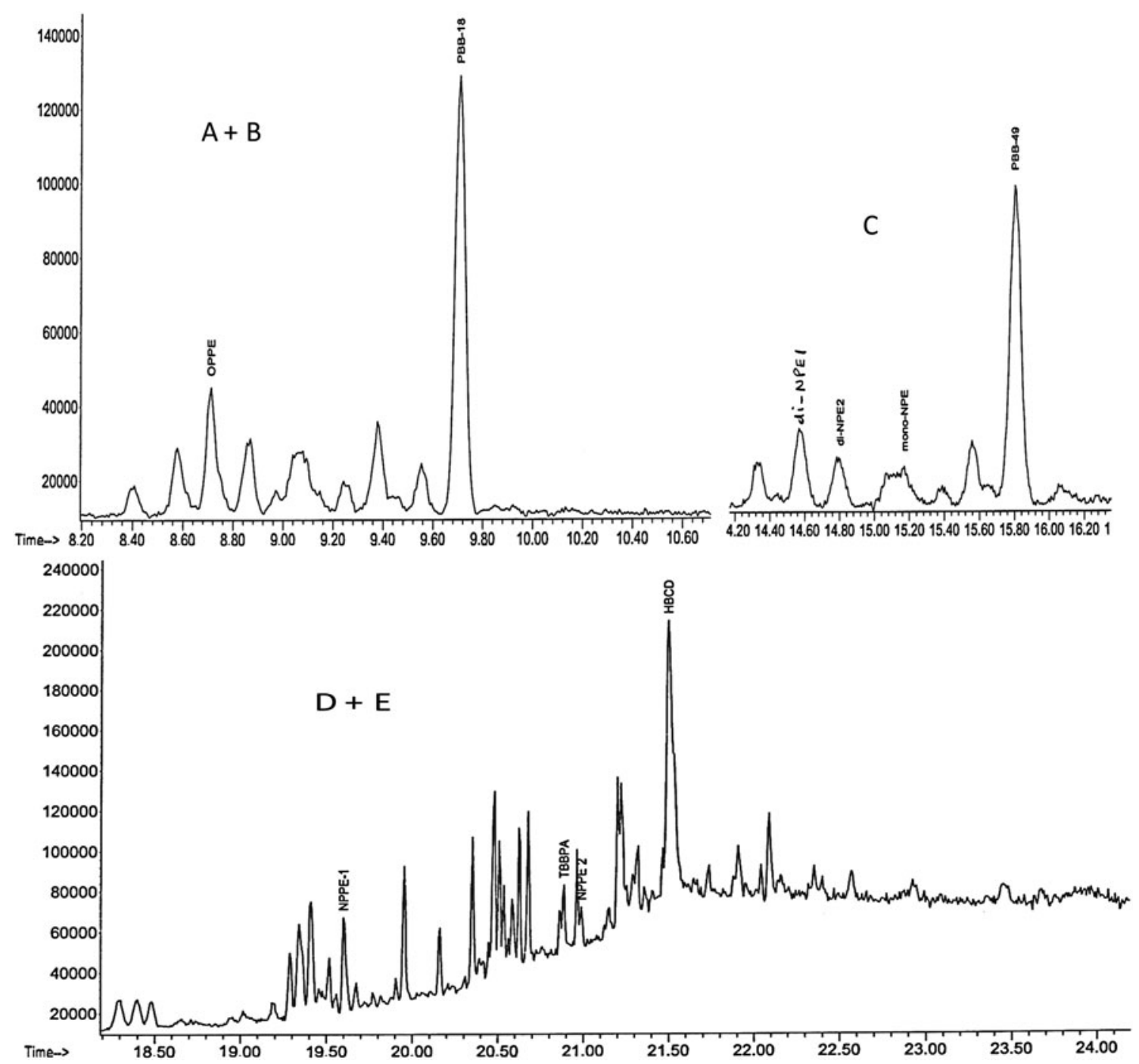

Fig. 7 Expanded peaks of $(A+B)$ OPPE and PBB18; $(C)$ di-NPE(1+2), PBB49; and $(D+E)$ NPPE-1, TBBPA, NPPE-2 and HBCD

obtained ranged from $65 \pm 7.07 \%$ for PBB-1 to $167.82 \pm 6.63 \%$ for mono-NPE. Because of this high recovery and abundance of molecular ions during the development, the internal standard addition method was not used. Recoveries greater than $100 \%$ of some analytes (i.e. PBB10, OPE, NPE and NPPE) may be because standards of technical grade were used instead of analytical grade which could not be sourced. With the exception of NP which exhibited a recovery of $66 \%$, all the target analytes in these study showed comparable recoveries with those reported [18, 21, 23, 25].

\section{Limits of Detection and Quantification}

In order to evaluate the experimentally found optimum conditions, linearity, limit of detection and quantification were determined. Linearity was checked by preparation of five different concentration levels from the APEs and BFRs standards. The relative standard deviations for the percentage recoveries as indicated in Table 5 were lower than $30 \%$ except for NPPE-1 which was $35 \%$. This indicated a good repeatability of the extraction. The targeted analytes were quantified by peak area abundance using external standard method. A five point calibration curves were linear $\left(r^{2}=0.98\right)$ across the concentration range of $0.2-1.0 \mu \mathrm{g} \mathrm{L}^{-1}$. As shown in Table 6, the calibration curves had good linear relationships using the standard solutions at five different concentration levels. The detection limits for the target analytes ranged from 0.01 (PBB-1) to 0.20 (di-NPE-2) at $95 \%$ confidence level. Gatidou et al. [21] and Diaz et al. [22] found the LOD for NP, mono-NPE and di-NPE to be $0.02,0.34$ and $0.41 \mu \mathrm{g} \mathrm{L}^{-1}$, respectively, 
compared to LOD of $0.02,0.15$ and $0.30 \mu \mathrm{g} \mathrm{L}^{-1}$, respectively, obtained in this present study. These values (for NP, mono-NPE and di-NPE) were also comparable with the values obtained by Azevedo et al. [26].

\section{Recoveries of APEs and BFRs in Wastewater Samples}

In order to properly validate the method used in the present study, as well as the impact of filtration before and after spiking with standard test reagents, recovery experiments were performed on wastewater samples collected from a treatment plant. To accomplish this, extraction, derivatization and GC-MS procedures described earlier were repeated. The results are given in Table 7 . The percentage recoveries in effluent ranged from $52.50 \pm 2.13$ to $168.75 \pm 4.05 \%$ while in the influent ranged from $32.50 \pm 5.35$ to $107.50 \pm 3.53 \%$. When the influent water sample was filtered and spiked prior to SPE extraction and derivatization, it was observed that the recoveries of the target analytes improved as compared to when the influent was spiked and then filtered. The slight improvement in recoveries was attributed to the removal of particulate materials that may have retained the target analytes in the influent spiked and filtered sample. The effluent recoveries were comparable to the results reported [21].

Levels of APEs and BFRs in the Environmental Samples

The developed method was successfully applied to wastewater samples taken from the wastewater treatment plant in order to determine the concentrations of the target compounds in the water samples. The chromatograms of the analytes are shown in Fig. 7, and their concentrations in Table 8. From Fig. 7, the peaks were fairly separated. As seen in Table 8, most of the target compounds determined in the samples were obtained at levels lower than those found in other studies [21] except for di-NPE1, mono-NPE, NPPE1 and NPPE2 with concentrations ranging from 10.268 to $10.615 \mu \mathrm{g} \mathrm{L}^{-1}, 3.014$ to $16.373 \mu \mathrm{g} \mathrm{L}^{-1}, 5.553$ to $15.156 \mu \mathrm{g} \mathrm{L}^{-1}$ and 13.449 to $21.971 \mu \mathrm{g} \mathrm{L}^{-1}$, respectively, in both filtered and unfiltered samples. However, as observed by Sibali et al. [6], there were no appreciable differences between filtered and unfiltered wastewater samples from Leeuwkuil treatment plant although concentration of target analytes in filtered influent water was slightly lower than the concentration of target analytes in unfiltered influent raw water. Also the concentrations of the analytes in the effluent were generally lower than the concentrations in filtered and unfiltered influent samples.
Table 8 Concentrations of APEs and BFRs in wastewater samples

\begin{tabular}{|c|c|c|c|}
\hline $\begin{array}{l}\text { Corrected data } \\
\text { compound }\end{array}$ & $\begin{array}{l}\text { Effluent } \\
\left(\mu \mathrm{g} \mathrm{L}^{-1}\right)\end{array}$ & $\begin{array}{l}\text { Influent } \\
\left(\mu \mathrm{g} \mathrm{L}^{-1}\right)\end{array}$ & $\begin{array}{l}\text { Influent raw } \\
\left(\mu \mathrm{g} \mathrm{L}^{-1}\right)\end{array}$ \\
\hline$t$-BP & ND & ND & 0.095 \\
\hline n-BP & ND & ND & ND \\
\hline HXP & ND & ND & ND \\
\hline$t$-OP & ND & ND & 0.105 \\
\hline PBB-1 & ND & ND & ND \\
\hline HPP & ND & ND & ND \\
\hline $\mathrm{OP}$ & ND & ND & ND \\
\hline PBB-10 & ND & ND & ND \\
\hline NP & ND & ND & ND \\
\hline OPE & ND & ND & 0.092 \\
\hline OPPE & 1.461 & 4.566 & 4.259 \\
\hline PBB-18 & ND & ND & ND \\
\hline PBB-49 & ND & ND & ND \\
\hline di-NPE2 & ND & ND & 6.474 \\
\hline di-NPE1 & 0.550 & 10.615 & 10.268 \\
\hline mono-NPE & 2.092 & 3.014 & 16.373 \\
\hline NPPE1 & 0.972 & 5.553 & 15.156 \\
\hline TBBPA & 3.269 & 6.629 & 6.806 \\
\hline NPPE2 & 3.126 & 21.971 & 13.449 \\
\hline HBCD & 0.142 & 0.1400 & 0.139 \\
\hline
\end{tabular}

Effluent final water leaving the plant, influent raw water filtered then acidified and $\mathrm{MeOH}$ added, influent raw raw water acidified and $\mathrm{MeOH}$ added then filtered, $N D$ not detected

\section{Conclusions}

A simultaneous SPE extraction and derivatization followed by GC-MS method was developed for the determination of selected APEs and BFRs in wastewater treatment sample. The derivatization procedure involved the reaction of these compounds, simultaneously in the presence of lower congeners of PBBs and HBCD, with HFBA under $\mathrm{Na}_{2} \mathrm{CO}_{3}$ base at $55^{\circ} \mathrm{C}$ for $2 \mathrm{~h}$. SPE extraction and GC-MS analysis of the derivatized compounds gave sharp peaks with good and high sensitivity for the analytes. The GC-MS analysis was completed in less than $22 \mathrm{~min}$. The results of this study demonstrated that the represented method showed acceptable relative recoveries for the determination of APEs and BFRs in wastewater samples.

The developed method showed good recoveries of $65 \pm 7.07-167.82 \pm 6.63 \%$ for the target compounds and adequate LOD and LOQ that ranged from 0.01 to $0.20 \mu \mathrm{g}$ $\mathrm{L}^{-1}$ and 0.05 to $0.66 \mu \mathrm{g} \mathrm{L}^{-1}$, respectively. When the conditions developed were optimized and applied to environmental wastewater samples, the analytes were detected at low levels with the exception of nonylphenol pentaethoxylates (NPPE2) which gave inexplicable high 
concentration value. The presented method had shorter analysis time and was simple.

Acknowledgments The authors are indebted to Rand Water for providing the technical environment and funding for this project, $\mathrm{Mr}$. Carl Schoeman for fruitful discussions and Tshwane University of Technology for support.

Open Access This article is distributed under the terms of the Creative Commons Attribution License which permits any use, distribution, and reproduction in any medium, provided the original author(s) and the source are credited.

\section{References}

1. Rodriguez-Mozaz S, Lopez de Alda MJ, Barceló (2007) J Chromatogr A 1152:97. doi:10.1016/j.chroma.2007.01.046

2. Pedrovic M, Barceló D, Diaz A, Ventura F (2003) J Am Soc Mass Spectrom 14:516. doi:10.1016/S1044-0305(03)00139-9

3. Ying GG, Williams B, Kookana R (2002) Environ Int 28:215. doi:10.1016/S0160-4120(02)00017-X

4. Xie Z, Ebinghaus R (2008) Anal Chimica Acta 610:156. doi: 10.1016/j.aca.2008.01.055

5. Medina CM, Pitarch E, López FJ, Vazquez C, Hernández F (2008) Anal Bioanal Chem 390:1343. doi:10.1007/S00216007-1792-Z

6. Sibali LL, Okonkwo JO, McCrindle RI (2010) Water SA 34:611

7. Vetter W, von der Recke R, Symons R, Pyecroft R (2008) Rapid Commun Mass Spectrom 22:4165. doi:10.1002/rcm.3845

8. Polder A, Bester B, Skaare JV, Bouman H (2008) Chemosphere $73: 148$

9. Odusanya OD, Okonkwo JO, Botha B (2009) Waste Manag (Oxford) 29:96. doi:10.1016/j.wasman.2008.02.011
10. Hyötyläinent T, Hartonen K (2002) Trends Anal Chem 21:13. doi:10.1016/S0165-9936(01)00122-4

11. Olukunle OI, Okonkwo OJ, Kefeni KK, Lupankwa M (2011) Water Sci Technol 65:743. doi:10.2166/wst.2012.894

12. Leslie HA, Leonards PEG, Shore RF, Walker LA, Bersuder PRC, Morris S, Allchin CR, de Boer J (2011) Chemosphere 82:88. doi: 10.1016/j.chemosphere.2010.09.073

13. Polo M, Gomez-Noya G, Quintana JB, Llompart M, Garcia-Jares C, Cela R (2004) Anal Chem 76:1054. doi:10.1021/ac/0.0292x

14. Lacorte S, Ikonomou MG, Fischer M (2010) J Chromatogr A 1217:337. doi:10.1016/j.chroma.2009.11.024

15. Alaee A, Sergeant DB, Ikonomou MG, Luross JM (2001) Chemosphere 44:1489. doi:10.1016/S0045-6535-(00)00311-8

16. Ding WH, Tzing SH (1998) J Chromatogr A 824:79. doi:10.1016/ S0021-9673(98)00593-7

17. Li D, Park J, Oh JR (2001) Anal Chem 73:3089. doi:10.1021/ ac0014941

18. Hoai PM, Tsunoi S, Ike M, Kuratani Y, Kudou K, Viet PH, Fujita M, Tanaka M (2003) J Chromatogr A 1020:161. doi:10.1016/j. chroma.2003.08.064

19. Stehmann, Schöder HF (2004) Water Sci Technol 50:115

20. Pan YP, Tsai SW (2008) Anal Chimica Acta 624:247. doi: 10.1016/j.aca.2008.06.039

21. Gatidou G, Thomaidis NS, Stasinakis AS, Lekkas TD (2007) J Chromatogr A 1138:32. doi:10.1016/j.chroma.2006.10.037

22. Diaz A, Ventura F, Galceran MT (2002) Anal Chem 74:3869. doi:10.1021/ac020124p

23. Dirtu AC, Roosens L, Geens T, Gheorghe A, Neels H, Covaci A (2008) Anal Bioanal Chem 391:1175. doi:10.1007/soo216007-1807-9

24. Miller JC, Miller JN (1998) Statistics for analytical chemistry, 2nd edn. Ellis Horwood, Chichester

25. Cai Y, Jiang G, Liu L, Zhou Q (2003) Anal Chem 75:2517. doi: $10.1021 / \mathrm{ac} / 0263566$

26. Azevedo DA, Lacorte S, Viana P, Barceló D (2001) J Braz Chem Soc 53:113. doi:10.1059/S0103-50532001000400015 